\title{
Prediction of shape distortions during forming and welding of a double-curved strip geometry in alloy 718
}

\author{
Lluís Pérez Caro ${ }^{1,2}$ (D) Eva-Lis Odenberger ${ }^{1,2}$ - Mikael Schill ${ }^{3} \cdot$ Joachim Steffenburg-Nordenström ${ }^{4}$. \\ Fredrik Niklasson ${ }^{4} \cdot$ Mats Oldenburg ${ }^{2}$
}

Received: 19 October 2019 / Accepted: 18 February 2020 / Published online: 18 March 2020

(C) The Author(s) 2020, corrected publication 2020

\begin{abstract}
The finite element method (FEM) has considerably contributed to the development of advanced manufacturing methods for metal structures. The prediction of the final shape of a component is of great interest to the manufacturing industry. The level of demand may increase due to multistage processes. Therefore, including all steps of the manufacturing chain in the simulations is a key to being successful. This has been done for a long time in the stamping industry, which involves sequences of forming, trimming, and springback. However, more complex manufacturing procedures that include assembling of formed parts with forgings and castings via welding have been modelled with simplifications, resulting in a reduced prediction accuracy. In the present study, a double-curved part manufactured from alloy 718 is formed at $20^{\circ} \mathrm{C}$ and laser-welded using the bead-on-plate procedure. The coupling of different manufacturing analyses, including cold forming, trimming, result mapping, welding, cooling, and springback, is achieved using LS-DYNA. Additionally, the effect of adding a damage and failure model in the forming simulation is studied. The results of the forming analysis are used as inputs for the material model *MAT_CWM in the welding simulation. The anisotropic thermomechanical properties of alloy 718 are determined at temperatures up to $1000{ }^{\circ} \mathrm{C}$. Encouraging agreement is found between the model predictions and the results of forming and welding tests. The findings underscore the importance of including the material history and accurate process conditions along the manufacturing chain to both the prediction accuracy of shape distortions, and to the potential of the industry.
\end{abstract}

Keywords Forming $\cdot$ Welding $\cdot$ Alloy $718 \cdot$ Shape distortions $\cdot$ Anisotropy $\cdot$ High temperature measurements

\section{Introduction}

Virtual computer-aided engineering (CAE) tools have an increasing significance in the design and development of lightweight solutions in all kinds of industries. The ability to combine advanced materials and material states that constitute

Lluís Pérez Caro

lluis.perez.caro@ri.se

Eva-Lis Odenberger

eva-lis.odenberger@ri.se

Mikael Schill

mikael.schill@dynamore.se

Joachim Steffenburg-Nordenström

joachim.steffenburg-nordenstrom@gknaerospace.com

Fredrik Niklasson

fredrik.niklasson@gknaerospace.com future lightweight components and designs will largely depend on the ability to model advanced material behaviour and virtually evaluate special fabrication procedures to develop new manufacturing strategies. As illustrated in Fig. 1, the manufacture of static load-carrying aero-engine structures constitutes such an example, in which sheet metals are combined with

Mats Oldenburg

mats.oldenburg@1tu.se

1 Division of Materials and Production, RISE IVF AB, Vällaregatan 30, SE-293 38 Olofström, Sweden

2 Division of Mechanics of Solid Materials, Luleå University of Technology, SE-971 87 Luleå, Sweden

3 DYNAmore Nordic AB, Brigadgatan 5, SE-587 58 Linköping, Sweden

4 GKN Aerospace Engine Systems Sweden, SE-461 38 Trollhättan, Sweden 


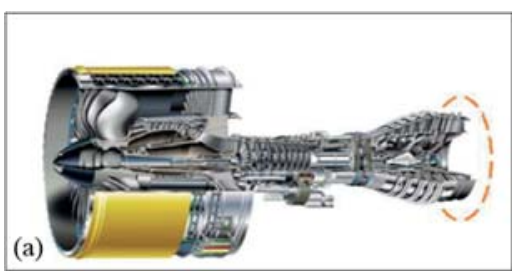

(b)

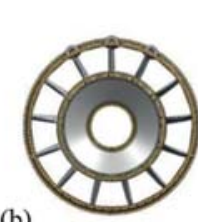

)

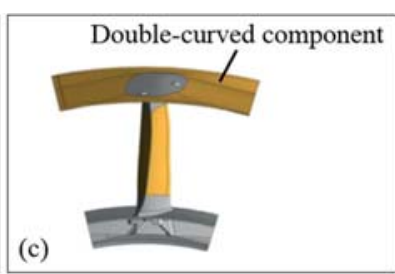

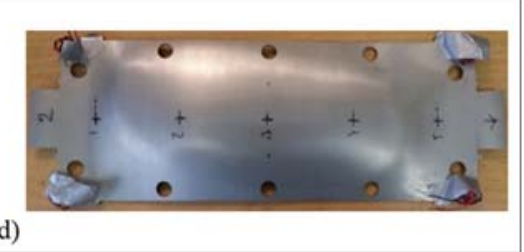

Fig. 1 a GP7000 turbine exhaust case (TEC) engine containing the studied component. b The TEC is a static load-carrying aero-engine structure consisting of 13 different sub-assemblies. c Detailed view of one of the sub-assemblies, indicating the location of the double-curved component. d Strip geometry (courtesy of GKN Aerospace Sweden) forgings and castings via welding and subsequent heat treatments. The double-curved component is of special interest because of the complexity in the manufacture and prediction of shape distortions during the fabrication of each sub-assembly, which requires a combination of forming and welding.

Individual manufacturing procedures, such as cold forming and assembly via welding and heat treatment, have been studied numerically to design suitable forming techniques or welding sequences with the purpose of minimizing shape distortions. Odenberger et al. [1] studied the compensation of deep-drawing prototype tools for springback in alloy 718 sheets, leading to a significant reduction of lead time, while maintaining high accuracy of the predicted shape deviations. By considering the anisotropic plastic properties of alloy 718 and including models for damage and failure, as Pérez Caro et al. [2] investigated, new suitable forming procedures have been developed. Additionally, thermomechanical finite element analyses (FEA) in studies on welding and heat treatments have greatly contributed to manufacturing processes in various industries. As outlined by Lindgren [3], the further development of the welding models has contributed to a better representation of the engineering applications in the past decades. For example, Lundbäck and Runnemalm [4] studied the effect of the electron-beam welding procedure on the shape distortions and residual stresses in alloy 718. Their model was able to accurately predict the amount of residual stresses as well as the distribution of the shape deviations over the parts. Fisk and Lundbäck [5] modelled repair welding and heat treatment in alloy 718 . The predicted welding temperatures and residual stresses were in good agreement with the experimental measurements. The effect of the welding fixture on the experimental and predicted distortions during welding was addressed by Ma et al. [6].

Many studies have been conducted on the prediction of shape distortions considering different combinations of the forming, welding, and heat treatment steps in a manufacturing process chain. Thomas et al. [7] predicted the springback and final shape of two different aluminium alloys in a manufacturing chain of forming and spot welding processes. Govik et al. [8] examined the springback behaviour of an assembly made of DP600 in a manufacturing process consisting of forming and spot welding. Additionally, Berglund et al. [9] and Tersing et al. [10] studied the welding and heat treatment steps in an industrial process involving martensitic stainless steel and Ti6Al-4V components for the aero-engine industry, respectively. Schill and Odenberger [11] also investigated the possibility of combining different process simulations in the manufacturing chain of an aerospace component made of alloy 718 . The major objective of this study was to develop methods for performing coupled simulations using different FE codes rather than to evaluate the prediction accuracy.

Steffenburg-Nordenström and Larsson [12] considered a manufacturing chain including forming, welding, and heat treatment of a V-shaped leading edge of a vane manufactured from alloy 718 . They concluded that the history of the material after forming had a considerable effect on the amount of residual stresses in the subsequent steps of the manufacturing process chain. Huang et al. [13] reported similar results in Q235 steel, concluding that the initial distortions from forming can largely influence the buckling distortion during welding. Papadakis et al. [14] studied the influence of preliminary manufacturing processes, i.e. forming, trimming, and welding, on the crash behaviour of automotive body assemblies made of bake hardening and dual phase steels. The predicted results from each step in the manufacturing chain, such as residual stresses, strains, and element thicknesses, were transferred into the next stage. They concluded that the predicted energy absorption of the assembly decreased when considering the history of the material from the preliminary steps in the manufacturing chain. Bauer et al. [15] investigated a forming and welding process chain of a DC04 tube. The transfer of the material and mechanical properties between processes ensured an accurate prediction of shape distortions, weld bed size, and residual stresses.

Nevertheless, considerable resources are still spent on compensating the final structure for shape distortions that occur during the welding and heat treatment procedures. These compensations are based on measurements performed after each manufacturing process step and are used to design suitable fixturing to accomplish welding of the different subassemblies that constitute the engine structure, see Fig. 1c. However, the influence from the prior manufacturing process steps to the subsequent shape distortions in the next procedure should not be neglected. To increase the prediction accuracy and to compensate the forming tooling virtually, the welding sequence and fixturing are of utmost importance. 
In this study, a strip geometry extracted from a doublecurved component manufactured from alloy 718 is analysed. The dimensions of the strip geometry are shown in Fig. 2. A forming and trimming procedure at $20^{\circ} \mathrm{C}$ is followed by laser welding of the strip geometry clamped onto a fixture, result mapping, cooling, and springback upon clamping release. The FE analyses are performed using LS-DYNA. This FE methodology involves different types of solvers and makes it possible to include the results from the forming analysis in the welding analysis by mapping the results from the forming to the welding element mesh, thereby providing a start state for welding that includes the thinning, effective plastic strains, residual stresses, history variables, and obtained geometry after forming. The material model *MAT_CWM is used for the welding simulation through the welding graphical user interface (GUI) provided in LS-PrePost v4.5. This work aims to investigate the potential and applicability of the described method to the industry, where the use of limited number of tests and available FE models is sufficient to predict the final shape of the component with high accuracy.

The thermomechanical elastic and anisotropic plastic properties of alloy 718 at temperatures up to $1000{ }^{\circ} \mathrm{C}$ are determined and included. The forming analysis is modelled and simulated at $20^{\circ} \mathrm{C}$ using the three-dimensional (3D)-scanned forming tool geometry and the anisotropic Barlat et al. [16] Yld2000-2D material model. Forming and welding tests are performed to produce a strip geometry in alloy 718 and provide experimental data, which are used to compare the numerical predictions with the accumulative shape distortions and temperatures during welding.

\section{Experimental work}

\subsection{Material}

The precipitation-hardenable nickel-based superalloy alloy 718 (UNS N07718) is studied in this work. The specific batch

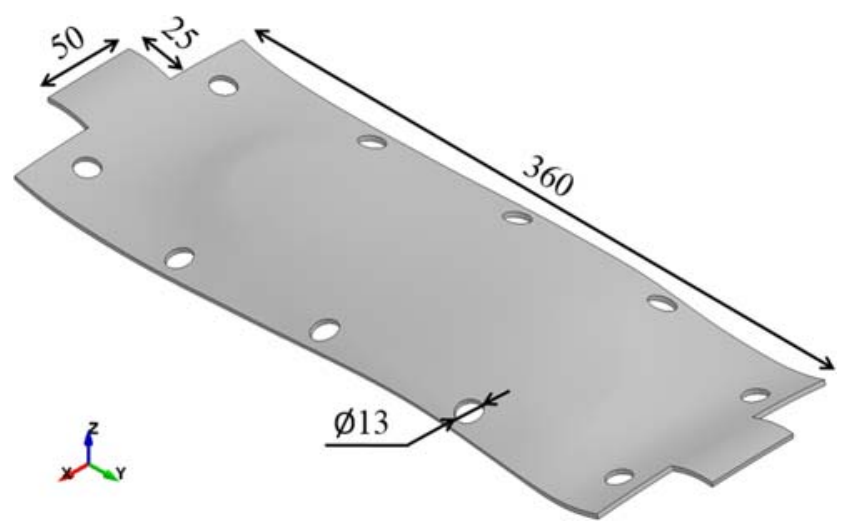

Fig. 2 Dimensions of the strip geometry. All measurements are expressed in millimetres of alloy 718 is delivered in form of $2.6 \mathrm{~mm}$ thick sheets, and in the solution-annealed condition according to the SAE AMS5596 specification. Table 1 presents the chemical composition of the alloy, as defined in the material certificate.

\subsection{Material characterization tests}

Uniaxial tension tests were performed in accordance with the SS-EN ISO 6892-1:2009 and SS-EN ISO 6892-2:2011 standards at temperatures between 20 and $1000{ }^{\circ} \mathrm{C}$. The specimens were laser cut in the longitudinal (L), diagonal (D), and transverse $(\mathrm{T})$ directions with respect to the rolling direction. The edges of the specimens were gently grinded to minimize the heat effect from the laser cutting procedure. The tests were conducted at two consecutive strain rates i.e. $0.0014 \mathrm{~s}^{-1}$ followed by $0.004 \mathrm{~s}^{-1}$ up to a technical strain of $0.2 \%$ and until fracture, respectively. Figure 3 shows the hardening curves. A stochastic pattern was applied on the surface of each specimen, and the deformations were continuously measured using the digital image correlation (DIC) system ARAMISTM . The frame rates were 12 and $4 \mathrm{~Hz}$. The facet size/step of $19 \times 15$ pixels defined the spatial resolution of the DIC images, and it was equivalent to an element size of $1 \mathrm{~mm}$. Each specimen was heated up to the target temperature with help of an induction coil. The temperature at the centre of the surface of the elevated temperature specimens was constantly measured and logged using an infrared sensor calibrated at each target temperature against a type $\mathrm{K}$ thermocouple with an accuracy of $\pm 1 \%$.

Tests to determine the Young's modulus (E) were performed in the $\mathrm{L}$ direction up to $700{ }^{\circ} \mathrm{C}$ via the impulse excitation technique (IET), where a vibration was induced in the specimen by a mechanical impulse, and the damping of each resonant frequency of the material was analysed [17]. The Young's modulus at each target temperature was predicted using simple linear regression, as presented in Fig. 4. Additionally, a silicon-rubber bulge test [18] was performed to determine the yield stress of the material for the balanced biaxial stress state.

\subsection{Validation tests}

Forming and welding validation tests were performed to correlate the numerical predictions with the measured values. Emphasis was placed on the shape distortions after forming and welding, together with temperature measurements during welding.

\subsubsection{Sheet metal forming and trimming}

The stretch-forming procedure was designed to introduce plastic straining in the blank in order to reduce the amount of springback. The forming tests were performed using a Fjällman hydraulic press with a pressing capacity of 
Table 1 Chemical composition of the alloy 718 studied (wt $\%$ )

\begin{tabular}{lllllllllll}
\hline $\mathrm{Ni}$ & $\mathrm{Fe}$ & $\mathrm{Cr}$ & $\mathrm{Nb}$ & $\mathrm{Mo}$ & $\mathrm{Ti}$ & $\mathrm{Al}$ & $\mathrm{Co}$ & $\mathrm{Mn}$ & $\mathrm{Si}$ & $\mathrm{Cu}$ \\
53.86 & 18.47 & 17.78 & 5.05 & 2.88 & 1.05 & 0.48 & 0.15 & 0.07 & 0.07 & 0.03 \\
$\mathrm{~V}$ & $\mathrm{~W}$ & $\mathrm{C}$ & $\mathrm{P}$ & $\mathrm{B}$ & $\mathrm{Ta}$ & $\mathrm{Zr}$ & $\mathrm{S}$ & $\mathrm{Nb}+\mathrm{Ta}$ & $\mathrm{Ti}+\mathrm{Al}$ & $\mathrm{Ni}+\mathrm{Co}$ \\
0.03 & 0.02 & 0.019 & 0.008 & 0.004 & $<0.01$ & $<0.01$ & $<0.0003$ & 5.06 & 1.53 & 54.01 \\
\hline
\end{tabular}

$7000 \mathrm{kN}$. Preceding the forming test, the measurement of the binder force was carried out using four calibrated load cells placed on the binder, at a forming velocity of $25 \mathrm{~mm} / \mathrm{s}$, up to a value of $2534 \mathrm{kN}$. The draw-in of the two formed parts was measured using a digital Vernier calliper and compared with the predicted values from the forming simulations. The measured draw-in was determined in the $\mathrm{x}$ and $\mathrm{y}$ directions, c.f. Figure 7, by measuring the distance from the tool edge to the blank as the blank was placed onto the binder and, in the same way, at the closed stage of the forming tool at the end of the forming procedure. The drawbeads were modelled as physical drawbeads to capture the effect of the binder closure to the draw-in. The strip geometry was extracted from the doublecurved component via laser cutting. Four reference points, located at the outer edges of the formed part, were produced at the end of the forming procedure to ensure the correct placement of the strip geometry during laser cutting.

The measured springback after forming was determined via 3D scanning using the Zeiss T-SCAN CS equipment, followed by a comparison of each part with the computer-aided design (CAD) nominal geometry. The reference points correspond to the same positions as the nodal constraints applied in the springback analysis, see Fig. 5.

\subsubsection{Laser welding}

In the final step of the manufacturing chain, the strip geometry was placed in a welding fixture consisting of an insulation material that can resist high temperatures and loadings. The component was then clamped onto the fixture using $10 \mathrm{M} 8$ bolts (12.9) tightened to $40 \mathrm{Nm}$ each. The contact between the bolts and the strip geometry was thermally insulated using washers with a thickness of $4 \mathrm{~mm}$ and made of the same material as the welding fixture. The part was then laserwelded using the bead-on-plate procedure with help of an IPG Photonics laser source, which was performed directly on the part without any filling material. A specific shielding gas was used to protect the heat-affected zone and the molten pool from contact with the atmosphere. The welding tests were performed by GKN Aerospace Engine Systems Sweden in Trollhättan. In the welding process, the material was heated above the melting temperature and fused together during cooling. The temperatures during welding were measured at five different positions along the welding path and logged using type $\mathrm{K}$ thermocouples, as shown in Fig. 6. The temperature histories for the five positions are presented in Fig. 15. The springback after welding was measured using the same procedure employed after forming.

\section{Numerical procedure}

The manufacturing process chain involves several steps, such as sheet-metal forming, trimming, mapping of the results from the forming to the welding shell-element mesh, springback, welding, cooling, and final springback.

\subsection{Sheet metal forming and trimming}

The single-action forming process to manufacture a doublecurved component in alloy 718 combines both stretchforming and deep-drawing techniques in which no material that has passed through the drawbeads enters the actual component geometry. Such material is trimmed off after forming.
Fig. 3 Hardening curves for alloy 718 at $20^{\circ} \mathrm{C}$ in the $\mathrm{L}, \mathrm{D}$, and $\mathrm{T}$ directions. The flow curves at elevated temperatures are only referenced to the $\mathrm{L}$ direction

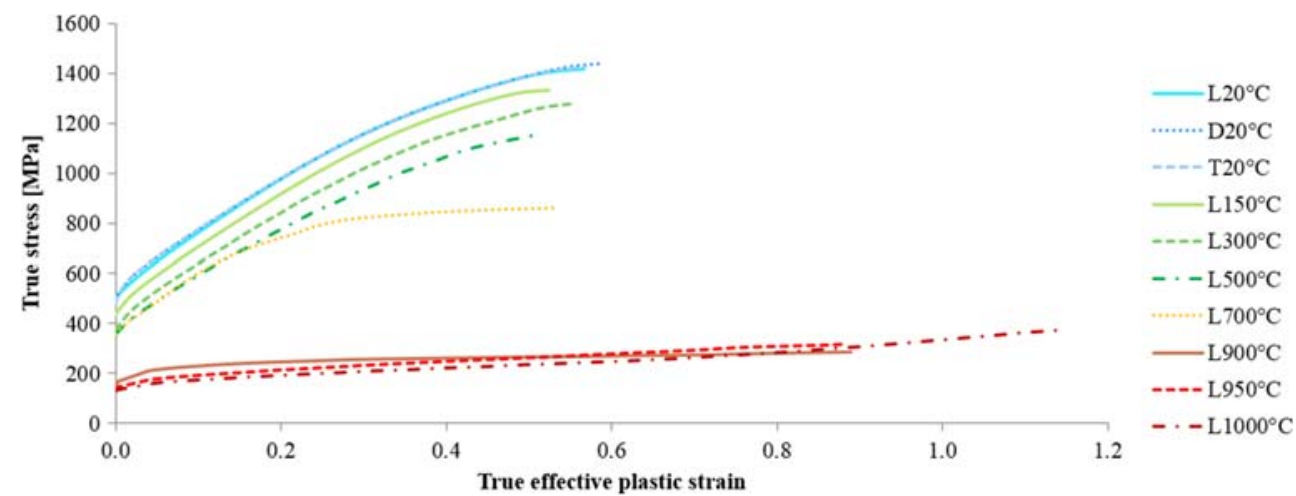


Fig. 4 Experimental Young's moduli for alloy 718 up to $700{ }^{\circ} \mathrm{C}$

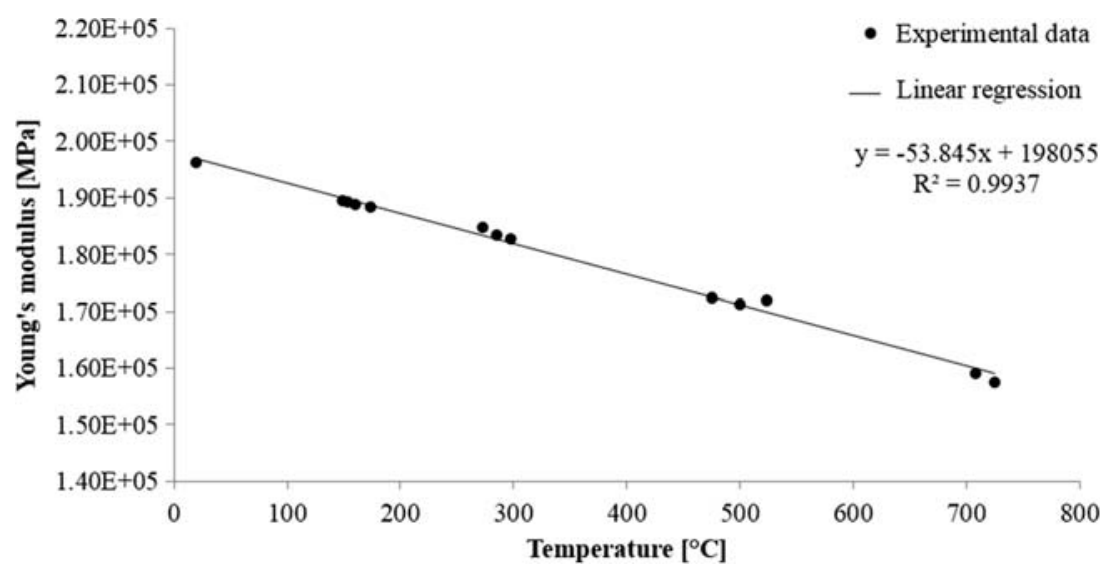

The tool setup was modelled in Dynaform v5.9.3 and analysed using the explicit solver in LS-DYNA R10.0.0 [19]. Figure 7 illustrates the FE model, which consisted of a punch, a die comprising an inner and outer tool parts that act as one complete tool part, a binder, and a blank. The binder included physical drawbeads in order to control the flow of the blank. The whole model contained 137,807 shell elements and 136,116 nodes. The total computational time was $7 \mathrm{~h}$ using 16 cores. The tool parts were built using initial graphics exchange specification (IGS) surfaces, and the drawbead heights and draw depth were adjusted in the model according to the results obtained from 3D scanning of the physical forming tool since the drawbead heights were modified during testing to avoid open fracture in one of the drawbeads.

The Barlat et al. [16] Yld2000-2D anisotropic yield criterion was used to model the forming procedure. The yield surface is described with eight anisotropic parameters, which were obtained through uniaxial tensile and bulge tests at $20{ }^{\circ} \mathrm{C}$. The obtained yield stresses and Lankford coefficients in Table 2 were inputted into the material model. The corresponding yield function $f$ can be described as follows:

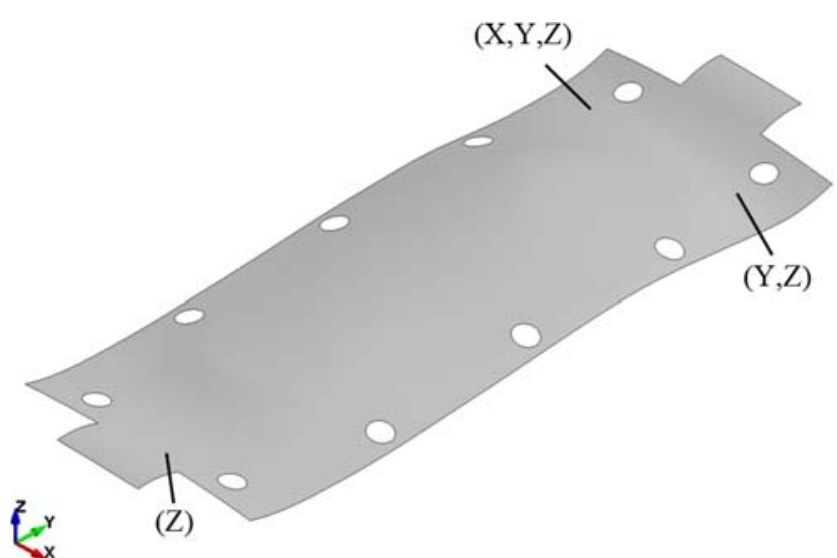

Fig. 5 Reference points and nodal constraints used in the springback measurements $f=\left|s_{1}-s_{2}\right|^{\mathrm{m}}+\left|2 s_{2}+s_{1}\right|^{\mathrm{m}}+\left|2 s_{1}+s_{2}\right|^{\mathrm{m}}-2 \bar{\sigma}^{m}=0$

where $\bar{\sigma}$ is the effective stress, $s_{i}$ are the principal deviatoric stresses, and $m$ is a parameter that describes the shape of the yield surface. Following the recommendations from Barlat and Lian [20] for materials with a face-centred cubic crystal structure (FCC), the parameter $m$ is set as 8 . To make an even more precise calibration of the shape edginess of the yield surface, additional tests to produce complementary reference points in the stress space are possible to conduct. However, the assumption of the yield surface exponent $m$ equal to 8 for anisotropic materials has been proven valid in forming of several types of materials such as aluminium, nickel-base superalloys, and titanium [1, 21, 22]. Also, it is desirable for the industry to reach accurate modelling predictions while increasing the efficiency in the calibration of material models by using a minimal number of material tests.

Equation 1 can be linearly transformed using $X=C \cdot s$ into the following equation:

$f=\left|\mathrm{C}^{\prime \prime} s_{1}-\mathrm{C}^{\prime \prime} s_{2}\right|^{\mathrm{m}}+\left|2 \mathrm{C}^{\prime \prime} s_{2}+\mathrm{C}^{\prime \prime} s_{1}\right|^{\mathrm{m}}+\left|2 \mathrm{C}^{\prime \prime} s_{1}+\mathrm{C}^{\prime \prime} s_{2}\right|^{\mathrm{m}}-2 \bar{\sigma}^{\mathrm{m}}=0$

where the matrices $\mathrm{C}^{\prime}$ and $\mathrm{C}^{\prime \prime}$ represent the linear transformations, which can be expressed by the anisotropic parameters listed in Table 2. The calibrated yield surface, initial yield stresses, and Lankford coefficients in the L, D, and T directions for alloy 718 at $20^{\circ} \mathrm{C}$ are shown in Fig. 8 .

The blank was modelled using 38,416 quadrilateral shell elements and 38,809 nodes. Each element was $4 \mathrm{~mm}$ in size and fully integrated (type 16) with seven through-thickness integration points. The h-adaptive method was used to automatically refine the mesh in areas with pronounced curvature and, therefore, increase the accuracy of the forming simulation while reducing computational time. Three maximum levels of 
Fig. 6 Welding test setup. Illustration of the formed and welded alloy 718 strip geometry attached in the welding fixture. The thermocouples are used to measure and log the temperatures at five different positions: $\mathrm{T} 1$ to T5. The arrow indicates the direction of the welding laser beam

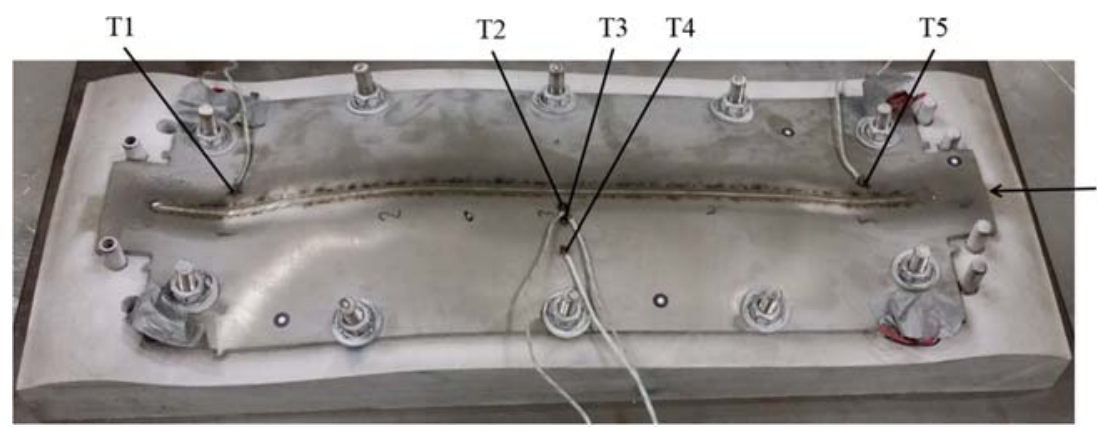

refinement yielded elements to a minimum size of $1 \mathrm{~mm}$ in areas where needed, i.e. the drawbeads and regions with marked draw radius. All tool surfaces were modelled as rigid. The die moved in the negative z-direction at a velocity of $1000 \mathrm{~mm} / \mathrm{s}$ during tool closure, i.e. when the drawbeads are formed, whereas the velocity was increased to $2000 \mathrm{~mm} / \mathrm{s}$ during the stretch-forming stage. The contact model between the blank and the tools followed the Coulomb's friction law. Figure $14 \mathrm{a}$ and $\mathrm{b}$ illustrates the simulated draw-in at the final stage of the forming procedure. The effect of adding the generalised incremental stress-state dependent damage model (GISSMO) proposed by Pérez Caro et al. [2] for the simulated draw-in was also studied, as shown in Fig. $14 \mathrm{c}$ and d. The GISSMO model assures that the effects of material failure, such as local thinning and strain localization, are captured during the forming procedure. The GISSMO model was calibrated including regularization for the mesh refinement during the FE analysis [2]. Based on the difference between the predicted and measured draw-ins for the two considered cases in Table 4, the friction coefficient was assumed 0.275 , similar to previous results by Wiklund and Larsson [23] using pin-ondisc tests. The procedure followed to estimate the value of the friction coefficient has been previously applied in forming procedures in titanium [22] and nickel-base superalloys [1].

After forming, a strip geometry was cut out using a 3D laser cutting procedure. The heat effect from the laser was attenuated after mildly grinding the outer edges of the test specimens. The trimming simulation was set up in Dynaform v5.9.3 with mesh refinement along the trimming edges. Figure 9 shows the formed blank with the trim line used to trim the blank and create the surfaces for remeshing before the welding analysis. The predicted and measured shape deviations after forming and trimming are illustrated in the results section, see Figs. 17a and 18.

\subsection{Mapping of results from forming to welding element mesh}

The mapping from the shell element mesh used in the forming analysis to the structured shell element mesh used in the welding analysis was performed using the mapping functionality in LS-PrePost v4.5. Figure 10 depicts the different meshes used. The forming mesh of the strip geometry contained 6,331 elements and 7,321 nodes. The density of
Fig. 7 FE tool setup with a detailed view of the mesh of the blank

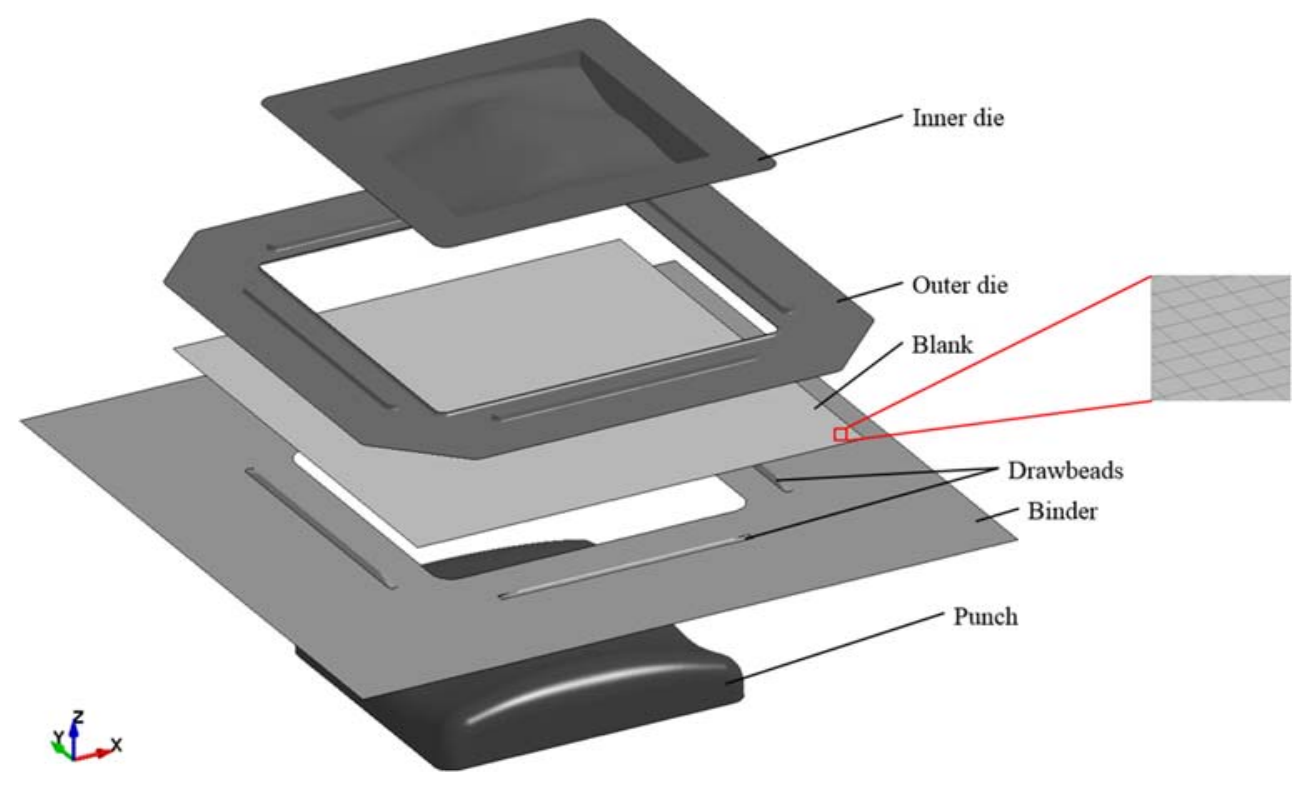


Table 2 Experimental input data for alloy 718 at $20^{\circ} \mathrm{C}$. The initial yield stresses $(\sigma$ in $\mathrm{MPa})$ and Lankford coefficients $(R)$ in the $\mathrm{L}, \mathrm{D}$, and $\mathrm{T}$ directions are based on the E-moduli from the IET tests. The eight anisotropic parameters $\left(\alpha_{\mathrm{i}}\right)$ for the Barlat material model are also included

\begin{tabular}{llllllll}
\hline$\sigma_{\mathrm{L}}$ & $\sigma_{\mathrm{D}}$ & $\sigma_{\mathrm{T}}$ & $\sigma_{\text {biaxial }}$ & $R_{\mathrm{L}}$ & $R_{\mathrm{D}}$ & $R_{\mathrm{T}}$ & $R_{\text {biaxial }}$ \\
502.43 & 489.87 & 480.56 & 538.00 & 0.761 & 0.912 & 0.960 & 1.0000 \\
$\alpha_{1}$ & $\alpha_{2}$ & $\alpha_{3}$ & $\alpha_{4}$ & $\alpha_{5}$ & $\alpha_{6}$ & $\alpha_{7}$ & $\alpha_{8}$ \\
0.8693 & 1.1190 & 0.8083 & 0.9929 & 0.9859 & 0.8372 & 1.0010 & 1.1580 \\
\hline
\end{tabular}

the mesh for the welding analysis was increased along the welding path, with a minimum size of $1 \mathrm{~mm}$ for the shell elements. The welding mesh then consisted of 16,539 elements and 16,475 nodes. The element type and number of integration points were preserved, and the initial stresses, shell thicknesses, and effective plastic strains were mapped to the new mesh, which included the nodal positions that correspond to the five thermocouples used to measure temperatures during welding, as shown in Fig. 6.

After mapping, the springback analysis was performed using the implicit method in LS-DYNA along with the nodal constraints in Fig. 5.

\subsection{Welding}

In the welding process, the material was heated above the melting temperature $\left(1260-1336^{\circ} \mathrm{C}\right)[24]$ and fused together during cooling. This was modelled using a coupled implicit thermal and mechanical solver in combination with a staggered approach, where the two solvers exchange results, allowing the two physical fields to affect each other. The total computational time was $50 \mathrm{~min}$ using 16 cores. As presented by Schill et al. [25], the setup for the welding analysis was constructed using the GUI for welding simulation available in LS-PrePost v4.5. The welding procedure was modelled using thermal and mechanical boundary conditions in accordance with the performed welding tests.

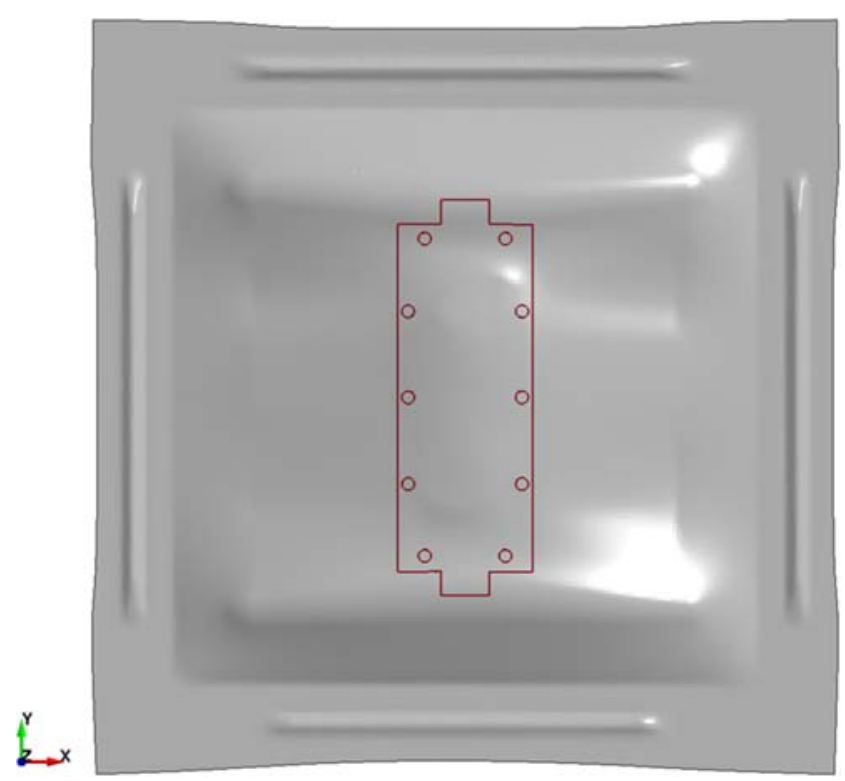

Fig. 9 Formed blank with the trim line (in red) used to trim the blank and obtain the strip geometry for remeshing before the welding analysis

The mechanical model included the part with the welding mesh obtained after mapping. The welding fixture was modelled as rigid, and nodal constraints were used in the zdirection to simulate the clamping of the formed alloy 718 component, as shown in Figs. 6 and 11. The clamping force applied to each M8 12.9 bolt on the fixture prior to welding was assumed to be $29 \mathrm{kN}$ applying a momentum of $40 \mathrm{Nm}$ [26]. The applied force in the welding test is way above the summarized axial force of the restricted nodes, see Fig. 11, which reached a maximum value of $859 \mathrm{~N}$ during the $\mathrm{FE}$ analysis. Both the thermal and mechanical contacts between the part and the fixture were included in the analysis. In the FE analyses, the welding laser beam moved toward the positive $y$ direction and followed the welding path.

The nonlinear implicit solver was used with a fixed timestep determined by the element length and weld speed. The timestep was advanced once per two elements
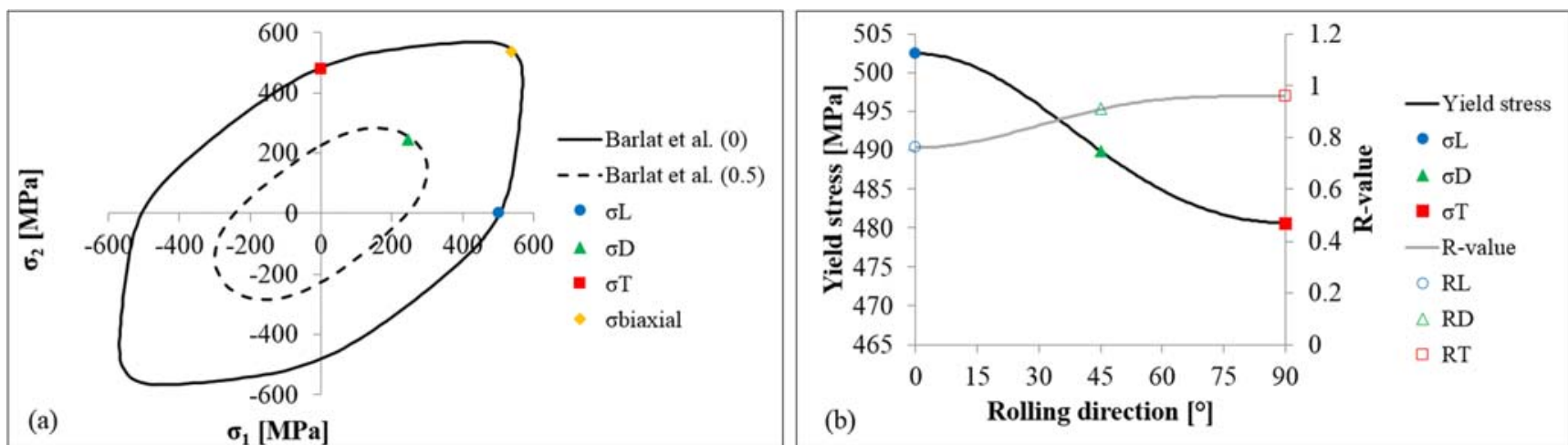

Fig. 8 a Calibrated yield surface for alloy 718 at $20{ }^{\circ} \mathrm{C}$ for various shear stress values $(0$ and 0.5$)$, with experimental reference points from uniaxial and biaxial tests. b Predicted and experimental initial yield stresses $(\sigma)$ and Lankford coefficients $(R)$ for the L, D, and T directions 
Fig. 10 Forming (left) and welding (right) meshes used in the FE analyses
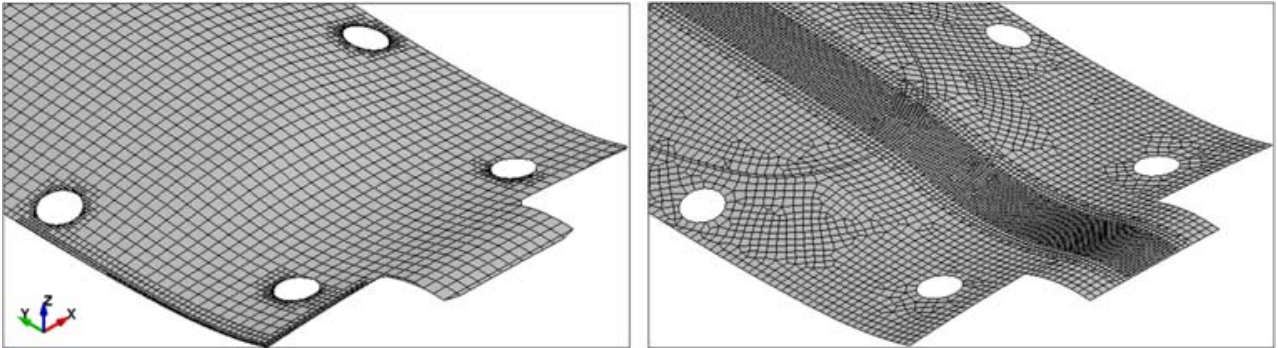

in the welding GUI. The thermo-elastoplastic material model *MAT_CWM was used for the welding simulations in LS-DYNA. Based on the isotropic von Mises yield criterion with linear hardening available in LSDYNA for welding simulations, the material has several welding capabilities, e.g. ghost and annealing functionalities. For ghost elements, the material has negligible thermal and mechanical properties until it is activated at a specified user-defined temperature. This is convenient for distinguishing between the three different material states: (i) solid - the material is always solid or a weld pass that has been previously activated; (ii) liquid-the material is in a ghost state but will be activated during the current weld pass; and (iii) ghost - the material that is not activated during the current weld pass but can be activated in a subsequent pass. In this study, no ghost material state was used, owing to the lack of filling material during the welding process. The annealing functionality is intended to simulate a limiting temperature range, i.e. $927-982{ }^{\circ} \mathrm{C}$, where the material behaves as an ideal elastic-plastic but with no evolution of plastic strains.
Thus, both the back stresses and effective plastic strains are set as zero. *MAT_CWM also includes a temperaturedependent thermal expansion coefficient.

The thermal weld part was modelled using thick thermal shell elements with a convection-to-air boundary condition, and a constant heat transfer coefficient of $20 \mathrm{~W} / \mathrm{m}^{2} \mathrm{~K}$ for the shielding gas. The thick thermal shell element allows for a quadratic variation of the temperature along the thickness of the shell. The insulation material for both the welding fixture and washers was considered to have a thermal conductivity of $0.71 \mathrm{~W} / \mathrm{mK}$. Each washer was assumed a heat transfer coefficient of $177.5 \mathrm{~W} / \mathrm{m}^{2} \mathrm{~K}$. The thermal contact between the blank and the welding fixture was utilized by modelling the fixture using thick thermal shell elements with the convection applied on the lower surface to represent the fixture thickness, as shown in Fig. 11. Hence, the heat transfer coefficient of the welding fixture was assumed to $28.4 \mathrm{~W} / \mathrm{m}^{2} \mathrm{~K}$. The temperature-dependent data used as the input to the *MAT_CWM, as illustrated in Fig. 12, were obtained from the simulation software JMatPro®-V9 for the specific chemical composition of alloy 718 , c.f. Table 1. Varying
Fig. 11 FE setup of the welding analysis with the mechanical nodal constraints in the $\mathrm{z}$ direction (in red) and the welding path (in yellow). The upper surface of the welding fixture in contact with the strip geometry is included, c.f. Figure 6. The opening in the centre of the fixture ensures that the shielding gas covers the entire length of the welding path. The direction of the welding laser beam is indicated by an arrow

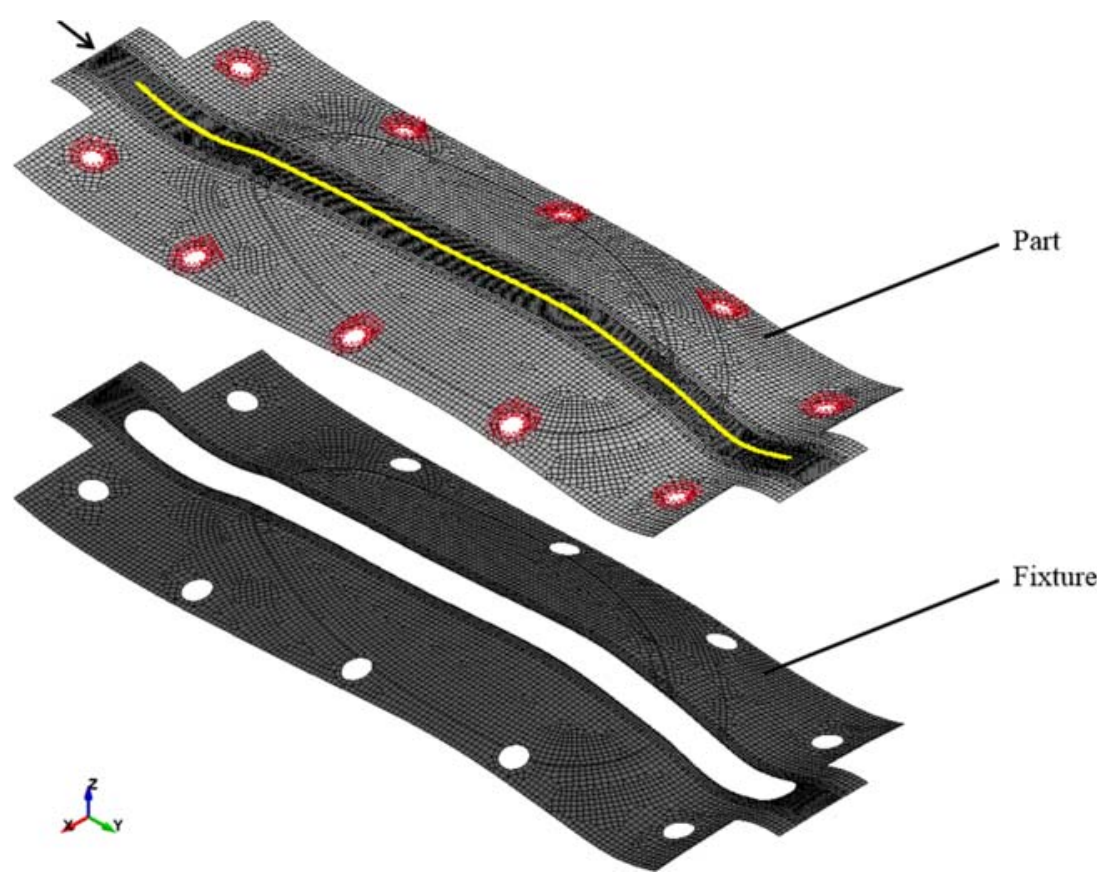


Fig. 12 Thermomechanical properties of alloy 718 in the welding FE analysis. a Thermal expansion coefficient. b Specific heat. c Poisson's ratio. d Thermal conductivity obtained from JMatPro®-V9. e The E-moduli at temperatures exceeding $700{ }^{\circ} \mathrm{C}$. The experimental E-moduli from the IET tests from 20 to $700{ }^{\circ} \mathrm{C}$ are shown in Fig. 4
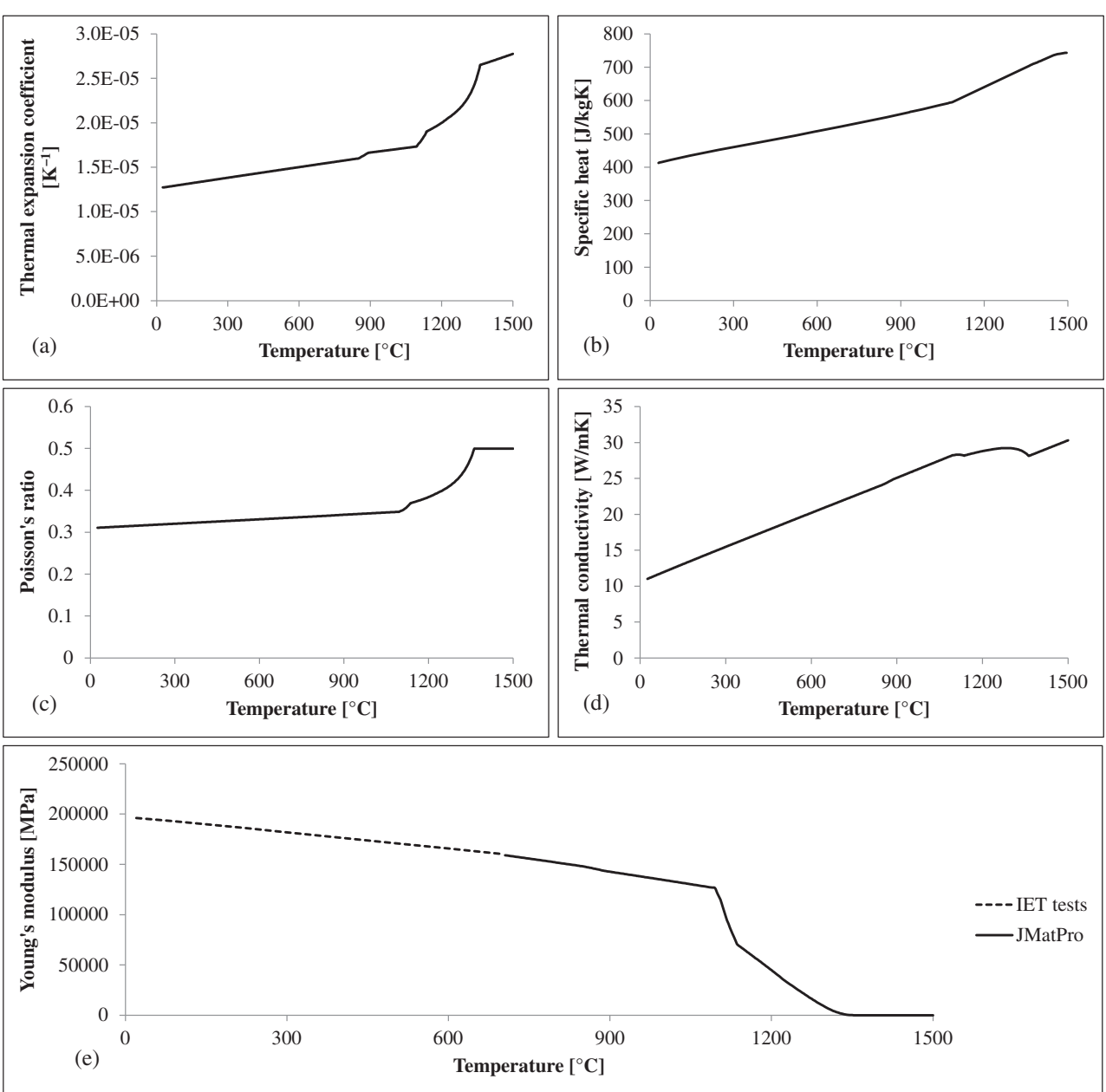

temperature dependency of the Young's modulus can be found in literature for alloy 718 [27, 28]; hence, the authors apply the IET values up to $700{ }^{\circ} \mathrm{C}$ and the JMatPro®-V9 predicted values at higher temperatures in which the chemical composition of the specific batch of alloy was considered. The tendency of the change of the Young's modulus with temperature is similar to Fukuhara and Sanpei [27]. The Goldak et al. [29] double-ellipsoid model was used for modelling the heat source, in which a volumetric heat load is applied to a volume

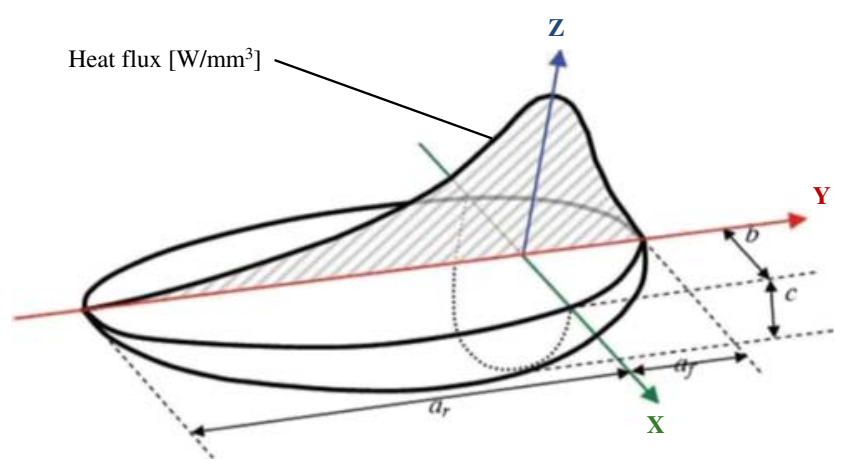

Fig. 13 Goldak double-ellipsoid heat source [25]. The parameters $a_{r}, a_{f}$, $b$, and $c$ are presented in Table 3 with an elliptic shape, as shown in Fig. 13. Based on the experiments, the parameters of the Goldak double ellipsoid presented in Table 3 were chosen to accurately mimic the laser weld heat source [5]. The weld speed in the analysis was $13.3 \mathrm{~mm} / \mathrm{s}$ under an applied weld power of $2.5 \mathrm{~kW}$, assuming an efficiency factor that accurately predicts the measured temperature history of the five thermocouples at different distances from the weld groove. The thermal solution was implicit, with the same fixed timestep as the mechanical solution.

\section{Results and discussion}

The effective plastic strains from each hardening curve for alloy 718 shown in Fig. 3 correspond to the small area of the specimen with the highest strain levels before failure.

Table 3 Parameters applied for the Goldak double-ellipsoid heat source model

\begin{tabular}{lllll}
\hline$Q(\mathrm{~W})$ & $a_{r}(\mathrm{~mm})$ & $a_{f}(\mathrm{~mm})$ & $b(\mathrm{~mm})$ & $c(\mathrm{~mm})$ \\
\hline 2500 & 5.80 & 2.30 & 2.50 & 2.84 \\
\hline
\end{tabular}


The E-moduli measured and predicted via the IET presented in Fig. 4 were used as a reference for determining the initial yield stresses at each temperature. In order to obtain suitable input data for the FE simulations, the hardening curves were smoothed using a user-defined code in MATLAB R2014b.

Figure 14 shows the simulated draw-in at the final stage of the forming procedure, both without and considering the GISSMO model. The predicted and measured draw-ins from the forming tests are presented in Table 4. The use of the GISSMO yielded marginally lower predicted draw-ins in all directions except for $\mathrm{Y} 2$, where the predicted draw-in was $30.43 \%$ higher than that in the case without the GISSMO model. This corresponds to the same drawbead region where microcracks and open fractures are detected in the forming tests at $20{ }^{\circ} \mathrm{C}$. The predicted draw-ins considering the GISSMO model were closest to the measured values for both parts in all testing directions, except for X2 in part 1 , see Table 4 . Hence, only the formed GISSMO geometry was considered in the subsequent stages in the manufacturing process chain.

Figure 15 presents a comparison between the measured and simulated temperatures at the five thermocouples during the welding tests. The predicted temperatures correlated well with the measured values close to the weld source, i.e. T1, T2, and T5. Small deviations were observed further from the weld source, i.e. T3 and T4. However, the resulting temperatures correlated well after some time.

The predicted effective plastic strains for all the steps of the manufacturing chain are presented in Fig. 16. The maximum strain levels in the formed part with the GISSMO model were
Table 4 Predicted and measured draw-ins in the directions X1 (left), X2 (right), Y1 (up), and Y2 (down) on the formed sheet. All measurements are expressed in millimetres

\begin{tabular}{llllll}
\hline & & \multicolumn{5}{l}{ Draw-in directions } \\
\cline { 3 - 6 } & & $\mathrm{X} 1$ & $\mathrm{X} 2$ & $\mathrm{Y} 1$ & $\mathrm{Y} 2$ \\
\hline \multirow{2}{*}{ Predicted } & Forming & 9.20 & -9.02 & 16.97 & -10.06 \\
& Forming + GISSMO & 9.18 & -8.82 & 16.80 & -13.12 \\
Measured & Part 1 & 8.43 & -9.37 & 16.74 & -12.48 \\
& Part 2 & 8.29 & -8.51 & 16.52 & -12.02 \\
\hline
\end{tabular}

$2.63 \%$ higher than those without it, as shown in Fig. 16a. As stated previously in this section, the results regarding the strip geometry are based on the forming simulation coupled with the GISSMO model. Previous work by Pérez et al. [2] shows the use of the GISSMO model in a forming simulation of a double-curved component when the presence of microcracks in some of the drawbeads could not be predicted using a forming limit diagram (FLD). The mapping of the results from the forming mesh in Fig. 16b to the welding mesh in Fig. 16c shows a marginal increase of $0.40 \%$ in the overall strain levels in the part. The welding, cooling, and subsequent springback increased the global effective plastic strains in the strip geometry by up to $3.28 \%$, as shown in Fig. 16d.

Figure $17 \mathrm{a}$ shows the predicted shape deviation after forming, trimming, and mapping. The corresponding results after welding, cooling, and springback are depicted
Fig. 14 Predicted draw-in at the final stage of the forming procedure $(\mathrm{a}, \mathrm{b})$ without and $(\mathrm{c}, \mathrm{d})$ including the GISSMO model. All measurements are expressed in millimetres

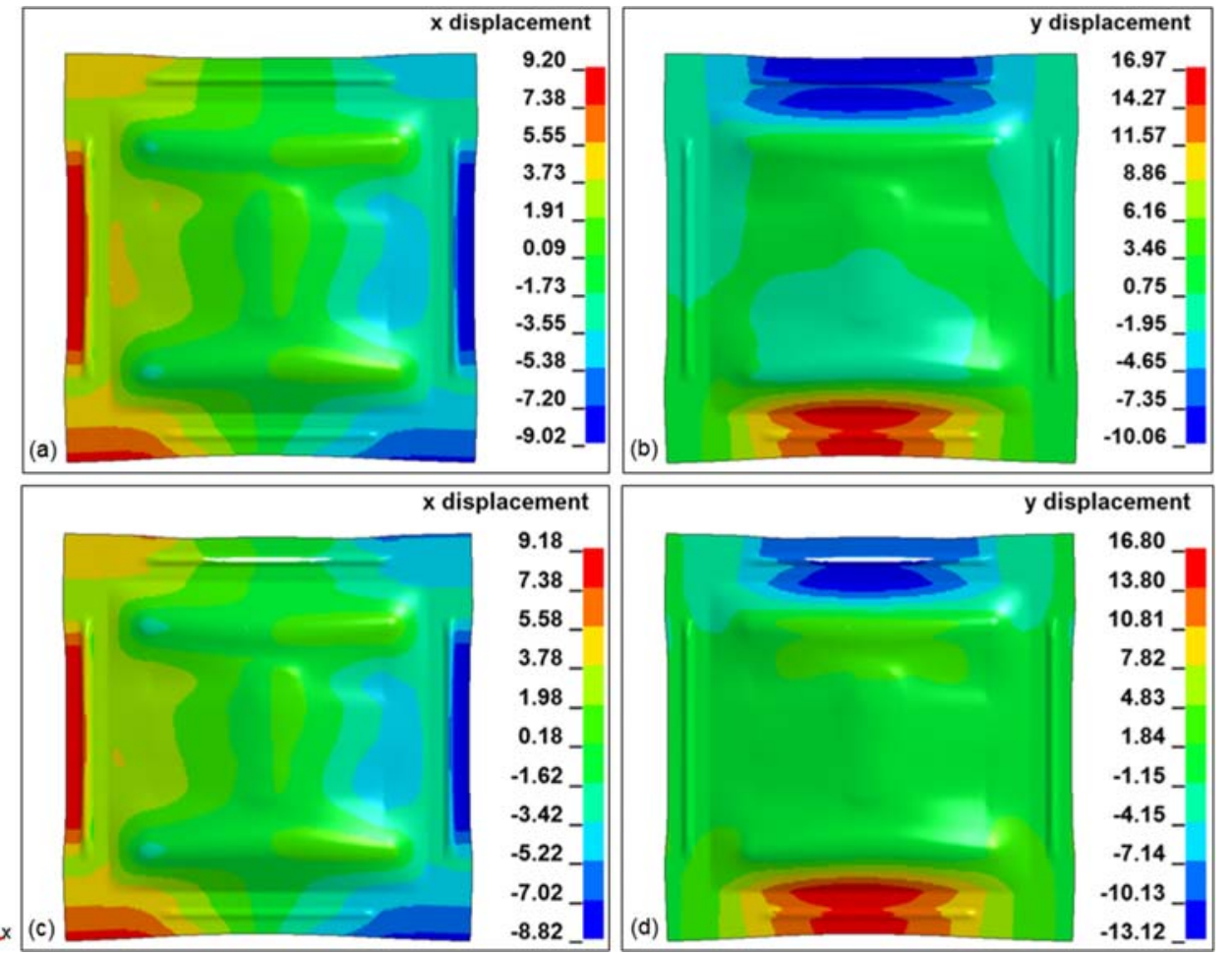


Fig. 15 Measured and predicted temperature histories during welding at the following positions. a T1. b T2. c T3. d T4. e T5
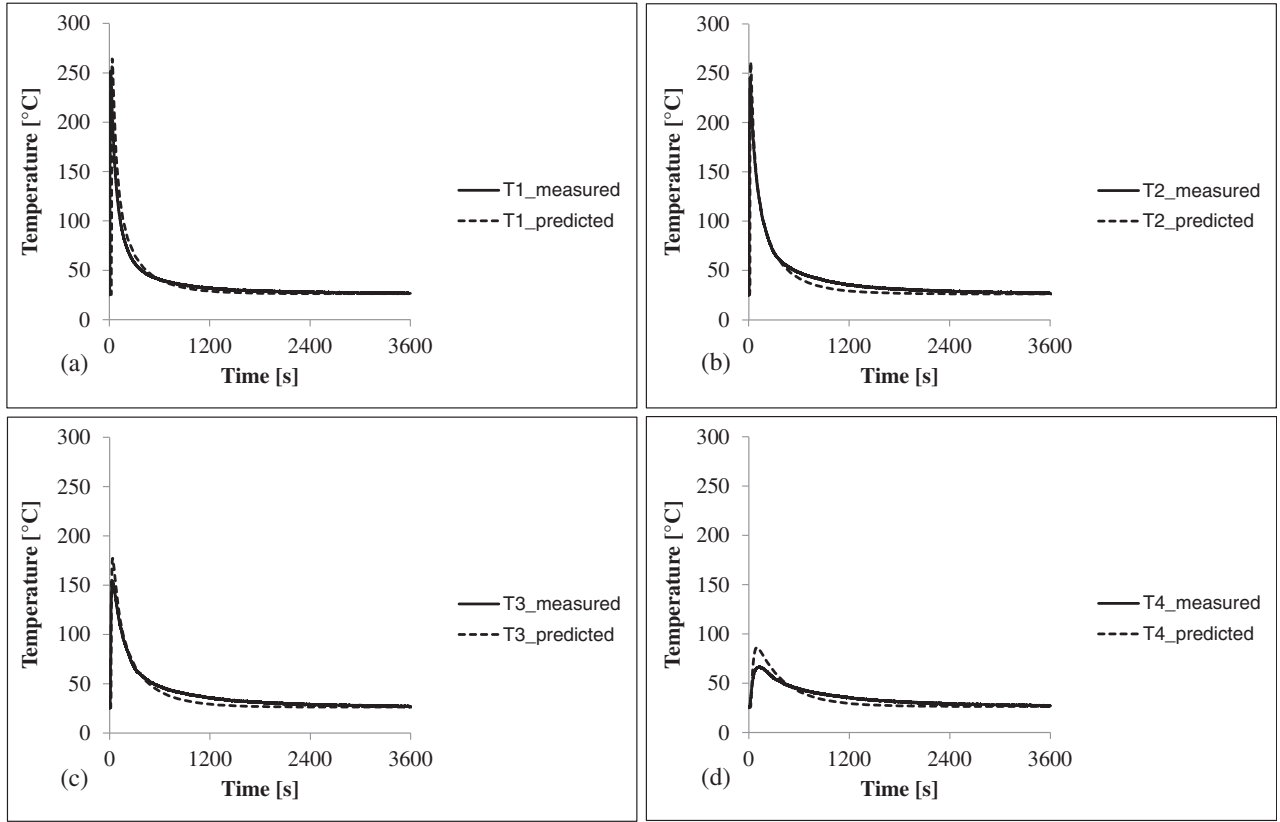

in Fig. 17b. For comparison purposes, the measured shape deviations after experimental forming and welding tests for the two parts are presented in Figs. 18 and 19, respectively. It is clear that the welding procedure, clamped with industry-like boundary conditions, introduces additional shape distortions in the parts. The major shape distortions originate from the effect of the heat source, melting the material as it progressively moves along the strip geometry, and altering the stress state in the part. Naturally, the fixturing will affect the amount of shape distortions obtained during welding. In this work, the purpose was not to identify an optimal fixturing design or welding strategy. Instead, the aim was to investigate if the shape distortions obtained from the welding experiments could accurately be predicted using FE analyses.

The distribution and magnitude of the experimental shape deviations of the two strip geometries were conformable with only minor deviance between the formed parts. In addition, the deviation in the measured draw-in after the forming of the two parts presented in Table 4 can be considered as small. The results of the forming simulation in Fig. 17a show the same tendencies of the distribution and magnitude as the experimental shape deviations of the two strip geometries depicted in Fig. 18. The closest agreement was observed at both the centre and right areas of the strip geometries, with a maximum deviation of $<0.5 \mathrm{~mm}$. The slight difference between the simulated and experimental shape deviations after forming may be within the expected reproducibility in the industrial fabrication procedure. The protruding earshaped geometries at the short ends of the parts exhibited larger deviations. However, these extensions were only used as the start and stop positions for the welding laser beam and were removed after the welding procedure.

As illustrated in Fig. 19, the subsequent welding procedure in the manufacturing chain introduces greater shape distortions in the parts. The predicted springback after welding in Fig. 17b captures the overall tendency of both the distribution and amount of shape distortions, especially in the central area of the strip geometries. In this case, the maximum difference between the simulated and experimental shape deviations after welding was < $1 \mathrm{~mm}$. The protruding areas exhibited larger deviations, 
Fig. 16 a Comparison of the effective plastic strains on the formed blank without (left) and including (right) the GISSMO damage model. The strain fields at the other stages of the manufacturing chain, i.e. $\mathbf{b}$ after forming and trimming, $\mathbf{c}$ after mapping and springback, and $\mathbf{d}$ after welding, cooling, and final springback, are based on the results for the formed part with the GISSMO model

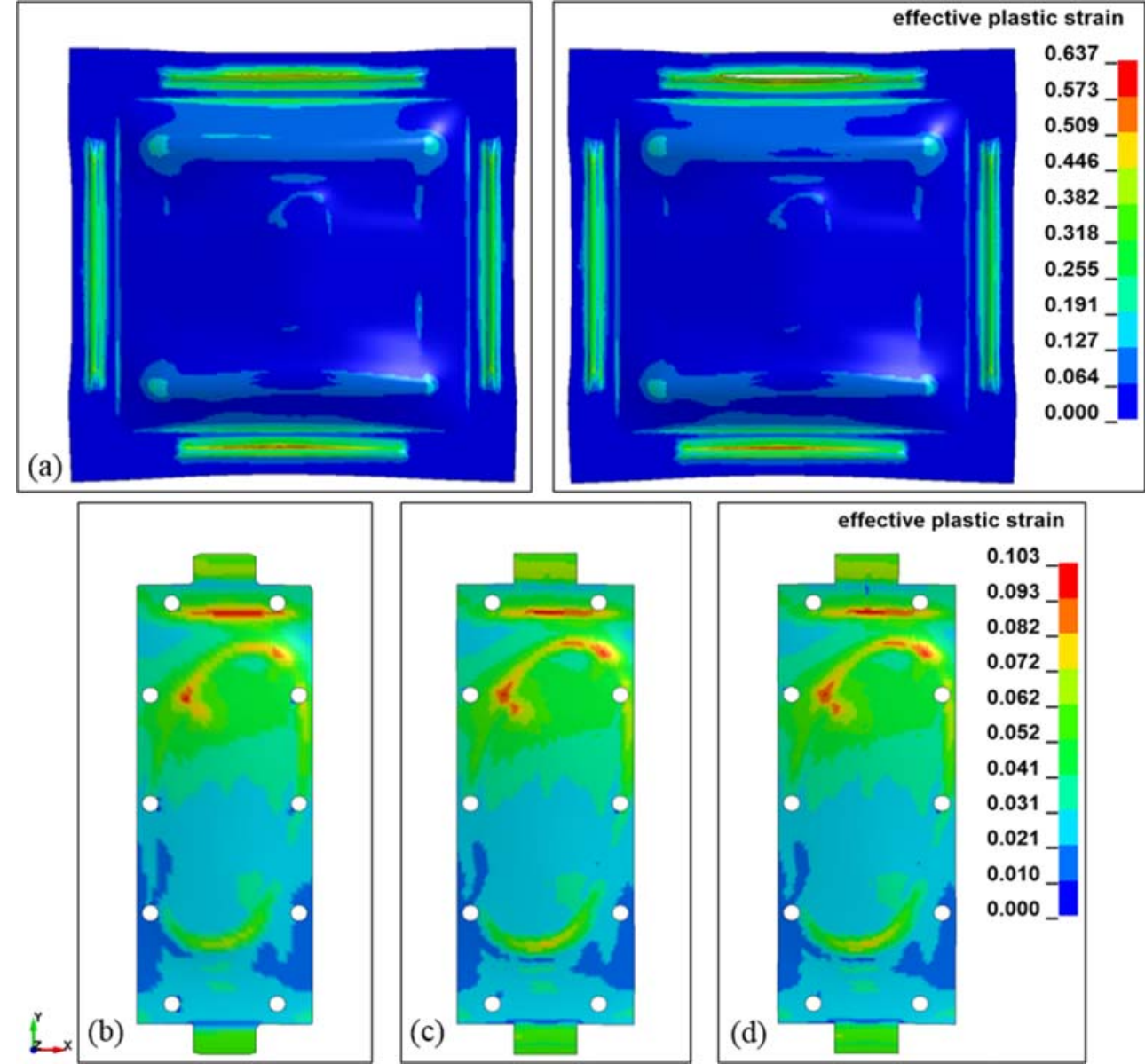

\section{Conclusions}

In the present study, the history from the sheet-metal forming procedure was used as the input for the subsequent welding of a double-curved strip geometry in alloy 718 . The major findings are listed as follows:

- Both the tendencies and magnitudes of the shape distortions of the forming and welding processes were well captured despite the simplicity in the calibration of the anisotropic yield criterion, estimation of the Coulomb's
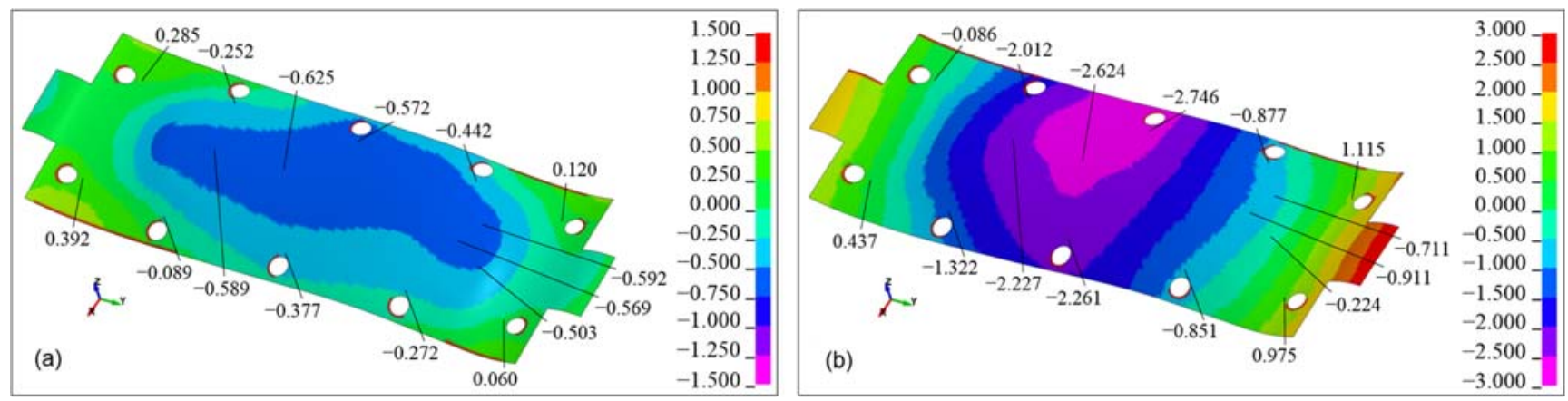

Fig. 17 Predicted shape deviations (a) after forming and (b) after welding. All measurements are expressed in millimetres 

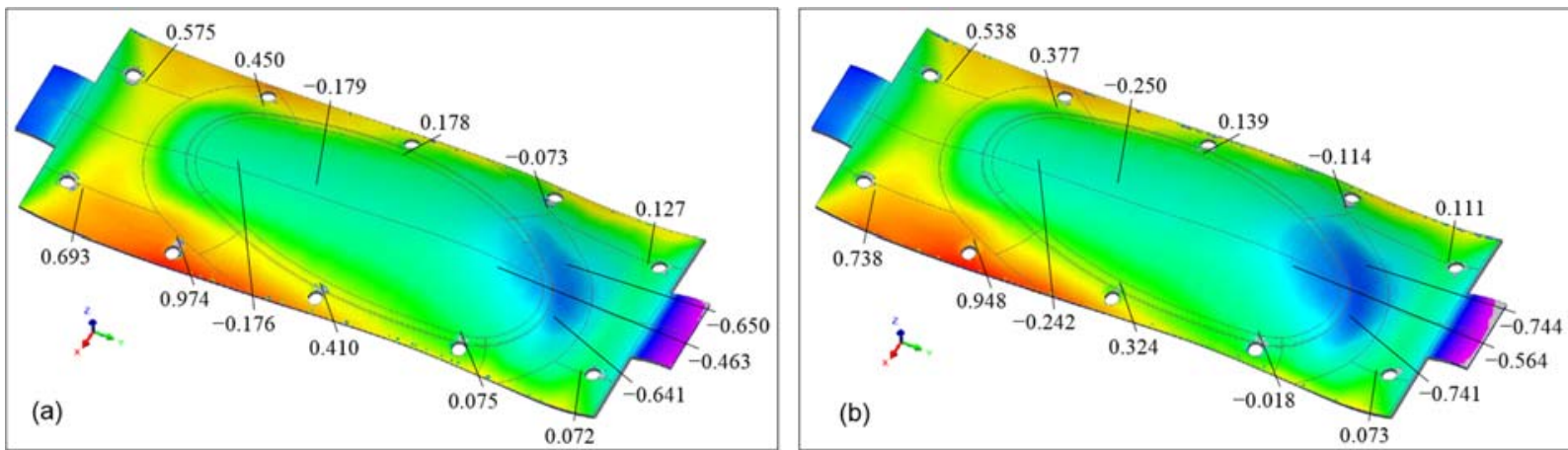

Fig. 18 Measured shape deviations after forming of (a) part 1 and (b) part 2. All measurements are expressed in millimetres

friction coefficient, and isotropic linear hardening in the welding material model.

- The effect of the GISSMO model from Pérez Caro et al. [2] on the forming simulations was examined, revealing a better agreement with experiments regarding draw-in and springback.

- The predicted shape deviation after welding exhibited encouraging agreement with the measured values. The small disparity between the predicted and measured responses after coupled forming and welding were within the expected reproducibility in production, indicating that the model accuracy is sufficiently high.

- The presented FE methodology, in which great care was taken to obtain equivalent conditions in the simulations and experiments, could greatly support the industrial development of future manufacturing procedures for lightweight designs in which new advanced materials are combined in an optimal way.

An engineering method was used to estimate a suitable value of the friction coefficient that was representative for the conditions existing in the specific forming procedure. The work also applies the assumption of a Coulomb's friction model with a constant friction coefficient, well-known not being able to capture the complex nature of the friction conditions existing in a forming procedure. The friction coefficient depends on several factors, such as material transport velocity, contact pressure, temperature, surface structure, and plastic straining in the sheet material. These factors continuously alter during the forming procedure. Different test procedures exist to determine values of the static and dynamic friction coefficient under controlled testing conditions, such as pin-on-disc, bending-under-tension (BUT), and strip-tension tests. To further increase the accuracy in the model predictions of forming and to be able to fully utilize the results from such friction tests, a more advanced friction model would be desirable. For example, the phenomenological friction model developed by Wiklund and Larsson [23] could constitute an interesting alternative.

The change from an anisotropic yield criterion in the forming analysis to the isotropic von Mises yield criterion with linear hardening in the welding analysis implies a reduced ability to accurately describe the material behaviour during welding. Even though the use of the thermoelastoplastic FEM in the welding simulation may be more computational costly than other prediction methods, such as the elastic FEM approach coupled with the large deformation theory by Deng and Murakawa [30], the use of a nonlinear coupled mechanical-thermal solver allows the simulation of the welding procedure with high accuracy.
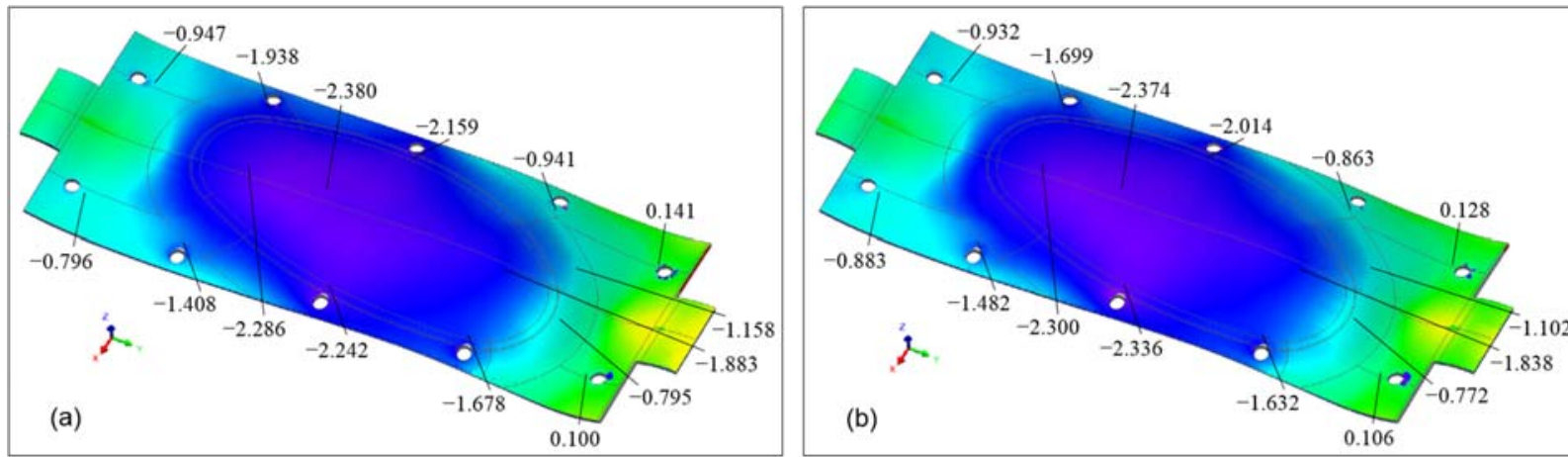

$-3.000$

Fig. 19 Measured shape deviations after welding of (a) part 1 and (b) part 2. All measurements are expressed in millimetres 
Acknowledgements Open access funding provided by Lulea University of Technology. The support from GKN Aerospace Sweden AB, ITE Fabriks AB, VINNOVA - Swedish Governmental Agency for Innovation Systems NFFP6 program for SME, Swedish Armed Forces, and Swedish Defence Materiel Administration is gratefully appreciated (grant no. 2013-01173).

Funding information This study was funded by VINNOVA - Swedish Governmental Agency for Innovation Systems NFFP6 program for SME, Swedish Armed Forces, and Swedish Defence Materiel Administration (grant number 2013-01173).

\section{Compliance with ethical standards}

Conflict of interest The authors declare that they have no conflict of interest.

Open Access This article is licensed under a Creative Commons Attribution 4.0 International License, which permits use, sharing, adaptation, distribution and reproduction in any medium or format, as long as you give appropriate credit to the original author(s) and the source, provide a link to the Creative Commons licence, and indicate if changes were made. The images or other third party material in this article are included in the article's Creative Commons licence, unless indicated otherwise in a credit line to the material. If material is not included in the article's Creative Commons licence and your intended use is not permitted by statutory regulation or exceeds the permitted use, you will need to obtain permission directly from the copyright holder. To view a copy of this licence, visit http://creativecommons.org/licenses/by/4.0/.

\section{References}

1. Odenberger EL, Jansson M, Thilderkvist P, Gustavsson H, Oldenburg M (2008) A short lead time methodology for design, compensation and manufacturing of deep drawing tools for Inconel 718. Olofström, Sweden. Proceedings of the IDDRG 2008 conference: best in class stamping. 1-12

2. Pérez Caro L, Schill M, Haller K, Odenberger EL, Oldenburg M (2019) Damage and fracture during sheet-metal forming of alloy 718. Int J Mater Form 12:1-14. https://doi.org/10.1007/s12289018-01461-4

3. Lindgren LE (2001) Finite element modeling and simulation of welding. Part 1-3. J Therm Stress 24:141-192. https://doi.org/10. 1080/01495730150500442

4. Lundbäck A, Runnemalm H (2005) Validation of threedimensional finite element model for electron beam welding of Inconel 718. Sci Technol Weld Join 10:717-724. https://doi.org/ 10.1179/174329305X48347

5. Fisk M, Lundbäck A (2012) Simulation and validation of repair welding and heat treatment of an alloy 718 plate. Finite Elem Anal Des 58:66-73. https://doi.org/10.1016/j.finel.2012.04.002

6. Ma N, Huang H, Murakawa H (2015) Effect of jig constraint position and pitch on welding deformation. J Mater Process Technol 221:154-162. https://doi.org/10.1016/j.jmatprotec.2015.02.022

7. Thomas D, Galbraith C, Bull M, Finn M (2002) Prediction of springback and final shape in stamped automotive assemblies: comparison of finite element predictions and experiments. Paris, France. Proceedings of the International body engineering conference and exhibition and automotive and transportation technology congress. https://doi.org/10.4271/2002-01-2063

8. Govik A, Nilsson L, Moshfegh R (2012) Finite element simulation of the manufacturing process chain of a sheet metal assembly. J
Mater Process Technol 212:1453-1462. https://doi.org/10.1016/j. jmatprotec.2012.02.012

9. Berglund D, Alberg H, Runnemalm H (2003) Simulation of welding and stress relief heat treatment of an aero engine component. Finite Elem Anal Des 39:865-881. https://doi.org/10.1016/ S0168-874X(02)00136-1

10. Tersing H, Lorentzon J, Francois A, Lundbäck A, Babu B, Barboza J, Bäcker V, Lindgren LE (2012) Simulation of manufacturing chain of a titanium aerospace component with experimental validation. Finite Elem Anal Des 51:10-21. https://doi.org/10.1016/j. finel.2011.10.002

11. Schill M, Odenberger EL (2014) Simulation of residual deformation from a forming and welding process using LS-DYNA®. Detroit, USA. Proceedings of the $13^{\text {th }}$ International LS-DYNA users conference

12. Steffenburg-Nordenström J, Larsson M (2014) Simulation of the influence of forming on residual stresses and deformations after welding and heat treatment in alloy 718. Barcelona, Spain. Proceedings of the $11^{\text {th }}$ World congress on computational mechanics $/ 5^{\text {th }}$ European conference on computational mechanics $/ 6^{\text {th }}$ European conference on computational fluid dynamics. 1657-1666

13. Huang H, Yin X, Feng Z, Ma N (2019) Finite element analysis and in-situ measurement of out-of-plane distortion in thin plate TIG welding. Materials 12:141-158. https://doi.org/10.3390/ ma12010141

14. Papadakis L, Schober A, Zaeh MF (2013) Numerical investigation of the influence of preliminary manufacturing processes on the crash behaviour of automotive body assemblies. Int J Adv Manuf Technol 65:867-880. https://doi.org/10.1007/s00170-012-4224-y

15. Bauer A, Manurung YHP, Sprungk J, Graf M, Awiszus B, Prajadhiana K (2019) Investigation on forming-welding process chain for DC04 tube manufacturing using experiment and FEM simulation. Int J Adv Manuf Technol 102:2399-2408. https://doi. org/10.1007/s00170-019-03320-1

16. Barlat F, Brem JC, Yoon JW, Chung K, Dick RE, Lege DJ et al (2003) Plane stress yield function for aluminium alloy sheets - part 1: theory. Int J Plast 19:1297-1319. https://doi.org/10.1016/S07496419(02)00019-0

17. IMCE (2017) RFDA professional. https://www.imce.eu/products/ rfda-professional. Accessed 20 March 2019

18. Sigvant M, Mattiasson K, Vegter H, Thilderkvist P (2009) A viscous pressure bulge test for the determination of a plastic hardening curve and equibiaxial material data. Int J Mater Form 2:235-242. https://doi.org/10.1007/s12289-009-0407-y

19. Hallquist JO (2006) LS-DYNA theory manual. Livermore Software Technology Corporation. https://www.dynasupport.com/ manuals/additional/ls-dyna-theory-manual-2005-beta. Accessed 3 October 2019

20. Barlat F, Lian J (1989) Plasticity behaviour and strechability of sheet metals. Part I: a yield function of orthotropic sheets under plane stress condition. Int J Plast 5:51-56. https://doi.org/10.1016/ 0749-6419(89)90019-3

21. Jansson M, Nilsson L, Simonsson K (2005) On constitutive modelling of aluminum for tube hydroforming applications. Int $\mathrm{J}$ Plasticity 21:1041-1058. https://doi.org/10.1016/j.ijplas.2004.06. 005

22. Odenberger EL, Schill M, Oldenburg M (2013) Thermomechanical sheet metal forming of aero engine components in Ti$6 \mathrm{Al}-4 \mathrm{~V}-$ part 2: constitutive modelling and validation. Int J Mater Form 6:403-416. https://doi.org/10.1007/s12289-012-1094-7

23. Wiklund D, Larsson M (2018) Phenomenological friction model in deep drawing of aluminum sheet metals. Waterloo, Canada. Proceedings of the $37^{\text {th }}$ International deep-drawing research group conference - IDDRG 2018. IOP Conf Ser Mater Sci 418:1-8. https://doi.org/10.1088/1757-899X/418/1/012097 
24. Special Metals Corporation (2007) High performance alloys literature - INCONEL® alloy 718. Special Metals Corporation SMC045. https://www.specialmetals.com/tech-center. Accessed 12 October 2019

25. Schill M, Jernberg A, Klöppel T (2016) Recent developments for welding simulations in LS-DYNA $®$ and LS-PrePost $₫$. Detroit, USA. Proceedings of the $14^{\text {th }}$ International LS-DYNA users conference

26. Colly Components AB (1995) Handbok om skruvförband. ISBN 91-630-3882-X

27. Fukuhara M, Sanpei A (1993) Elastic moduli and internal frictions of Inconel 718 and Ti-6Al-4V as a function of temperature. J Mater Sci Lett 12:1122-1124. https://doi.org/10.1007/BF00420541

28. Aba-Perea PE, Pirling T, Withers PJ, Kelleher J, Kabra S, Preuss M (2016) Determination of the high temperature elastic properties and diffraction elastic constants of Ni-base superalloys. Mater Des 89: 856-863. https://doi.org/10.1016/j.matdes.2015.09.152

29. Goldak J, Chakravarti A, Bibby M (1984) A new finite-element model for welding heat sources. Metall Trans B 15:299-305. https://doi.org/10.1007/BF02667333

30. Deng D, Murakawa H (2008) FEM prediction of buckling distortion induced by welding in thin plate panel structures. Comput Mater Sci 43:591-607. https://doi.org/10.1016/j.commatsci.2008. 01.003

Publisher's note Springer Nature remains neutral with regard to jurisdictional claims in published maps and institutional affiliations. 